\title{
Physical characteristics of ceramic/glass- polymer based CAD/CAM materials: Effect of finishing and polishing techniques
}

\author{
Mugem Asli Ekici', Ferhan Egilmez ${ }^{2 *}$, Isil Cekic-Nagas², Gulfem Ergun² \\ ${ }^{1}$ Department of Endodontics, ${ }^{2}$ Department of Prosthodontics, Faculty of Dentistry, Gazi University, Ankara, Turkey
}

\begin{abstract}
PURPOSE. The aim of this study was to compare the effect of different finishing and polishing techniques on water absorption, water solubility, and microhardness of ceramic or glass-polymer based computer-aided design and computer-aided manufacturing (CAD/CAM) materials following thermocycling. MATERIALS AND

METHODS. 150 disc-shaped specimens were prepared from three different hybrid materials and divided into five subgroups according to the applied surface polishing techniques. All specimens were subjected up to $\# 4000$ grit $\mathrm{SiC}$ paper grinding. No additional polishing has been done to the control group (Group I). Other polishing procedures were as follows: Group II: two-stage diamond impregnated polishing discs; Group III: yellow colored rubber based silicone discs; Group IV: diamond polishing paste; and Group V: Aluminum oxide polishing discs. Subsequently, 5000-cycles of thermocycling were applied. The analyses were conducted after 24 hours, 7 days, and 30 days of water immersion. Water absorption and water solubility results were analyzed by two-way ANOVA and Tukey post-hoc tests. Besides, microhardness data were compared by Kruskal-Wallis and MannWhitney $U$ tests $(P<.05)$. RESULTS. Surface polishing procedures had significant effects on water absorption and solubility and surface microhardness of resin ceramics $(P<.05)$. Group IV exhibited the lowest water absorption and the highest microhardness values $(P<.05)$. Immersion periods had no effect on the microhardness of hybrid ceramic materials $(P>.05)$. CONCLUSION. Surface finishing and polishing procedures might negatively affect physical properties of hybrid ceramic materials. Nevertheless, immersion periods do not affect the microhardness of the materials. Final polishing by using diamond polishing paste can be recommended for all CAD/CAM materials. [J Adv Prosthodont 2019;11:128-37]
\end{abstract}

KEYWORDS: Computer-aided design and computer-aided manufacturing (CAD/CAM); Hybrid ceramics; Dental polishing; Water hardness; Water solubility

\section{INTRODUCTION}

In the past few years, great achievements were gained especially in prosthetic dentistry regarding computer-aided

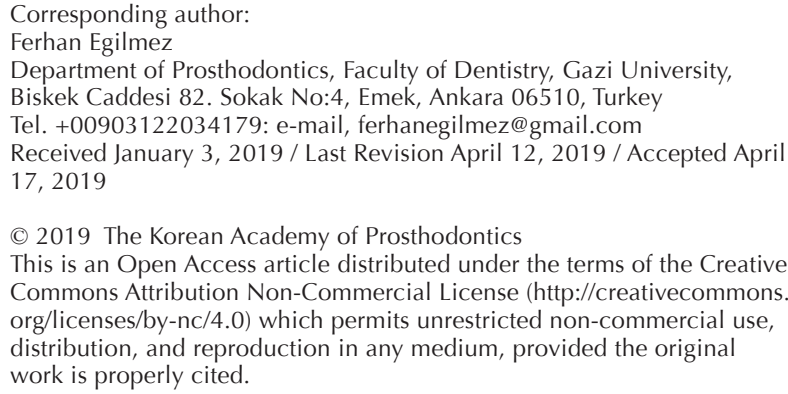

(C) 2019 The Korean Academy of Prosthodontics

This is an Open Access article distributed under the terms of the Creative Commons Attribution Non-Commercial License (http://creativecommons. org/licenses/by-nc/4.0) which permits unrestricted non-commercial use, distribution, and reproduction in any medium, provided the original work is properly cited.

This study was presented at the Turkish Dental Association 23rd International Dental Congress, Istanbul-Turkey, on September 21 - 24, 2017. design (CAD) / computer-aided manufacturing (CAM) technology. Currently, various esthetic CAD/CAM restorative materials including ceramic-, polymer-, or resin-based materials are available. ${ }^{1}$ The milling process of CAD/CAM restorations does not create a smooth surface ready for cementation. ${ }^{2}$ To create a smooth and biocompatible surface of the restoration, ceramic materials such as lithium disilicate glass ceramics, leucite-reinforced glass ceramics, feldspathic glass ceramics, aluminum-oxide, and yttrium tetragonal zirconia polycrystals require additional processing after milling, necessitating specialized equipment for sintering or firing and glazing. ${ }^{3}$ On the other hand, resin composite materials do not necessarily require those steps and can generally be finished with a readily available armamentarium in the dental office. ${ }^{4}$ Clinically, the insertion of the prosthesis requires verification and adjustment of the occlusion. In this context, subsequent polishing should be done following 
these adjustments for a long-term success. ${ }^{4}$

Although numerous advantages of resin-based materials, some disadvantages such as water absorption (WSP) and solubility (WSO) were previously reported. Water molecules, smaller than the interchain space in the resin, might diffuse through resin structure. ${ }^{5}$ The water uptake by the resin structure could cause filler-matrix debonding or even filler degradation. ${ }^{6}$ As a result, mechanical properties of the restorative material may be compromised. ${ }^{7}$ Therefore, WSP might play an important role in long-term stability of resin based CAD/CAM materials in an aqueous environment such as in the oral cavity. ${ }^{8}$

The physical degradation evidenced by material loss or uptake as a result of sorption, dissolution, and extraction, accompanied by material softening, stress cracking, and fatigue fracture have been extensively studied in dentistry. ${ }^{9}$ The hydrolytic degradation may cause dissolving or leaching out of unreacted monomers or fillers. ${ }^{10}$ The release of these components may influence not only the aesthetic aspect of the restoration, but also the clinical performance ${ }^{5}$ and the biocompatibility of the material. ${ }^{11}$ As one of the most important properties is the material hardness, which correlates well to compressive strength and abrasion resistance of resin based CAD/CAM materials, ${ }^{12}$ evaluation of WSP, WSO, and microhardness characteristics of current resinbased CAD/CAM materials become an important clinical issue especially after different polishing applications.

Therefore, the purpose of this study was to determine the WSP, WSO, and microhardness of different resin-based $\mathrm{CAD} / \mathrm{CAM}$ materials and to evaluate the effect of different surface finishing and polishing procedures on these properties. The major null hypotheses were threefold: 1 . There would be no difference in WSP and WSO properties of the tested materials; 2 . Surface finishing and polishing procedures would not affect WSP and WSO properties of the tested CAD/CAM materials. 3. Surface microhardness of the tested CAD/CAM materials would not differ following finishing and polishing procedures.

\section{MATERIALS AND METHODS}

Schematic study design is presented in Fig. 1. Fifty disc shaped specimens $(\varnothing=10 \mathrm{~mm}, \mathrm{~h}=1.5 \mathrm{~mm})$ of each of the three CAD/CAM materials were prepared $(\mathrm{N}=150)$. Tested materials, group codes, and their compositions are given in Table 1. Each specimen was polished with metallographic SiC papers (FEPA-P \#1200 and 4000) in order to achieve a similar degree of surface roughness in all specimens at the baseline under water cooling. Then the specimens were divided into 5 subgroups according to the applied polishing procedure ( $\mathrm{n}=10$ per group).

One experienced operator carried out the finishing and

Table 1. Materials and their specifications used in the study

\begin{tabular}{|c|c|c|c|c|}
\hline Type & Material & Group Code & Composition & Manufacturer \\
\hline Nano hybrid ceramic & GC Cerasmart & CS & $\begin{array}{l}\text { Composite resin material (BisMEPP }{ }^{\star}, \text { UDMA }^{\star \star} \text {, } \\
\left.\text { DMA }^{\star \star \star}\right) \text { with } 71 \text { wt\% silica and barium glass } \\
\text { nanoparticles }\end{array}$ & $\begin{array}{l}\text { GC Dental Products } \\
\text { Europe, Leuven, } \\
\text { Belgium }\end{array}$ \\
\hline Nano hybrid ceramic & Lava Ultimate & LU & 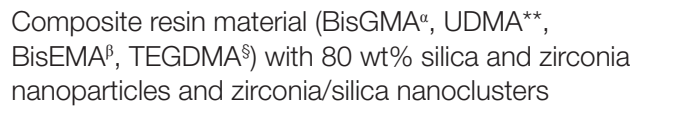 & $\begin{array}{l}\text { 3M ESPE, Seefeld, } \\
\text { Germany }\end{array}$ \\
\hline $\begin{array}{l}\text { Polymer infiltrated } \\
\text { ceramic }\end{array}$ & Vita Enamic & VE & $\begin{array}{l}\text { Polymer-infiltrated-feldspatic ceramic-network material } \\
\left(\text { UDMA }^{\star \star}, \text { TEGDMA }^{\S}\right) \text { with } 86 \text { wt\% ceramic }\end{array}$ & $\begin{array}{l}\text { VITA Zahnfabrik, } \\
\text { Bad Säckingen, } \\
\text { Germany }\end{array}$ \\
\hline $\begin{array}{l}\text { Metallographic } \\
\text { abrasive papers }\end{array}$ & $\begin{array}{l}\text { Silicon Carbide grinding } \\
\text { paper }\end{array}$ & Group I & $\begin{array}{l}\text { Paper coated with silicon carbide grains in resin } \\
\text { binder. } \# 1200 \text { grit (Grain size: } 14 \mu \mathrm{m} \text { ) and } \# 4000 \text { grit } \\
\text { (Grain size: } 5 \mu \mathrm{m} \text { ) }\end{array}$ & $\begin{array}{l}\text { FEPA-P; Struers, } \\
\text { Ballerup, Denmark }\end{array}$ \\
\hline $\begin{array}{l}\text { Two-stage diamond } \\
\text { impregnated polishing } \\
\text { discs }\end{array}$ & $\begin{array}{l}\text { EVE Diacomp Plus } \\
\text { Twist }\end{array}$ & Group II & Flexible diamond impregnated spirals & $\begin{array}{l}\text { EVE Ernst Vetter } \\
\text { GmbH; Pforzheim, } \\
\text { Germany }\end{array}$ \\
\hline $\begin{array}{l}\text { Yellow colored rubber } \\
\text { based silicone discs }\end{array}$ & $\begin{array}{l}\text { Polydentia (Yellow } \\
\text { silicone rubber polisher) }\end{array}$ & Group III & $\begin{array}{l}\text { Synthetic rubber, aluminum oxide, silicon carbide, } \\
\text { diamond powder }\end{array}$ & $\begin{array}{l}\text { Polydentia SA, } \\
\text { Mezzovico, } \\
\text { Switzerland }\end{array}$ \\
\hline $\begin{array}{l}\text { Diamond polishing } \\
\text { paste }\end{array}$ & Dia Polisher Paste & Group IV & $\begin{array}{l}\text { Glycerol, Silica powder, Zinc Oxide, Diamond Particles } \\
\text { (1 } \mathrm{mm} \text { grain sized) }\end{array}$ & $\begin{array}{l}\text { GC Dental Products } \\
\text { Europe, Leuven, } \\
\text { Belgium }\end{array}$ \\
\hline $\begin{array}{l}\text { Aluminum oxide } \\
\text { polishing discs }\end{array}$ & $\begin{array}{l}\text { Sof-Lex XT Extra-Thin } \\
\text { Contouring and } \\
\text { Polishing Discs }\end{array}$ & Group V & $\begin{array}{l}\text { Light orange (fine- } 24 \mu \mathrm{m} \text { grain size) and yellow (super } \\
\text { fine- } 8 \mu \mathrm{m} \text { grain size) flexible polishing discs with } \\
\text { aluminium oxide coating }\end{array}$ & $\begin{array}{l}\text { 3M ESPE, Seefeld, } \\
\text { Germany }\end{array}$ \\
\hline
\end{tabular}

*: 2,2-Bis (4-methyacryloxypolyethoxyphenyl) propane; ${ }^{* *}$ : Urethane dimethacrylate; ${ }^{* \star}$ : Dodecyl dimethacrylate; $\alpha:$ Bisphenol A diglycidylether dimethacrylate; $\beta$ : Ethoxylated bisphenol A dimethacrylate; §: Triethylene glycol dimethacrylate. 


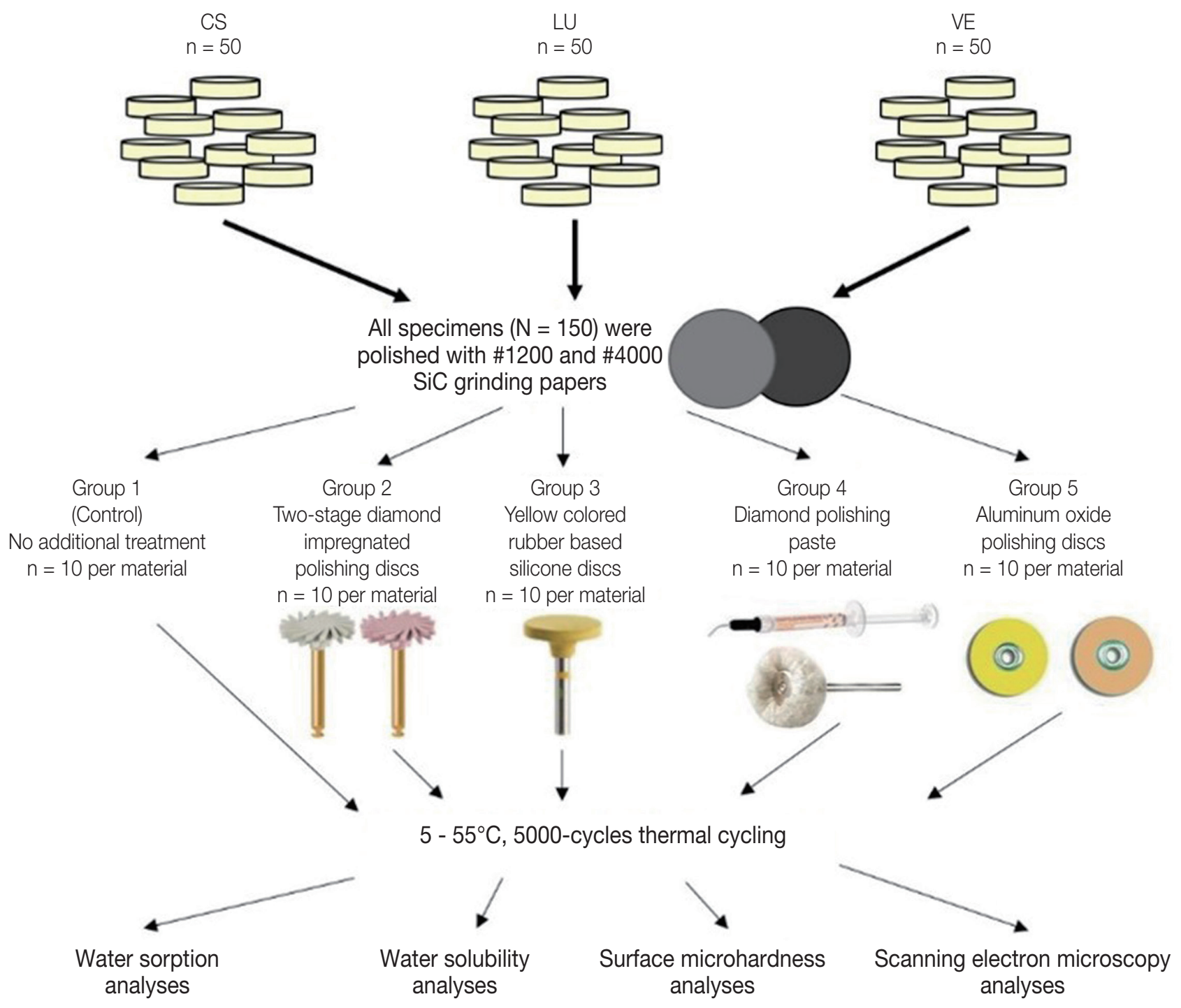

Fig. 1. Schematic study design.

polishing sequences simulating clinical procedures in accordance with the manufacturer's instructions for rpm and pressure. The same straight hand-piece and electric motor was used to control the rpm setting for each step. ${ }^{2}$

In this study, the specimens in Group I presented the control and no additional treatment was applied. Other groups received the following polishing procedures. The specimens in Group II were polished with diamond impregnated two-stage spiral polishing system (EVE Diacomp Plus Twist, EVE Ernst Vetter GmbH; Pforzheim, Germany). Pink and grey polishing wheels were sequentially applied in a mounted low speed handpiece under 10,000 rpm speed and light pressure for 15 seconds. In Group III, polishing was done with yellow colored rubber-based silicon abrasives (Polydentia, Polydentia SA, Mezzovico, Switzerland) using a low-speed handpiece with light pressure rotating at approximately 10,000 rpm for 15 seconds. The specimens in Group IV received final polishing by using diamond polishing paste (Diapolisher Paste, GC Dental Products Europe, Leuven, Belgium), goat-hair brushes and cotton buffs (Renfert $\mathrm{GmbH}$, Hilzingen, Germany) in a mounted low speed handpiece (Kavo Duratec 2068, Biberahc/Riss, Germany) on the specimen surface at 10,000 rpm speed and light pressure for 15 seconds. Finally, the specimens in Group V were sequentially polished with aluminum oxide abrasive discs (Sof-Lex XT Pop on, 3M ESPE, St. Paul, MN, USA), light orange (Fine $-24 \mu \mathrm{m}$ ) to yellow (Superfine $-8 \mu \mathrm{m}$ ) in a mounted low speed handpiece under light pressure for 15 seconds.

Polishing procedures selected for this study was applied 
on the top surface of each specimen and the specimens were rinsed with running water after each polishing step. All of the abrasives (abrasive papers, abrasive discs, rubbers, wheels and brushes) were discarded after every four specimens. The final thickness $( \pm 0.01 \mathrm{~mm})$ was measured with a digital caliper (Mitutoyo Corp, Kanogawa, Japan). The specimens were ultrasonically cleaned (Quantrex 90, L\&R Ultrasonics, Kearny, NJ, USA) for $10 \mathrm{~min}$ in deionized water in sequence and allowed to air dry for 24 hours at room temperature before testing. Thereafter, all of the specimens were submitted to thermocycling for 5000 cycles in a 5 $55^{\circ} \mathrm{C}$ water bath with a dwell time of 30 seconds and a transfer time of 5 seconds.

Water absorption (WSP) and solubility (WSO) were calculated in $\mu \mathrm{g} / \mathrm{mm}^{3}$ in accordance with ISO 4049:2009 ${ }^{13}$, for 24 hours, 7 days, and 30 days of water immersion time. The specimens were stored in a desiccator maintained at $37 \pm$ $1^{\circ} \mathrm{C}$. After 22 hours, specimens were removed and stored in a second desiccator maintained at $25 \pm 1^{\circ} \mathrm{C}$ for 2 hours and weighed in a digital balance (Precisa XB 220A, Precisa Instruments AG, Dietikon, Switzerland). This desiccation cycle was repeated until a constant mass (m1) was obtained. Following final drying, the diameter and height of each specimen were measured to calculate the volume.

After the initial desiccation procedure, specimens were immersed in $20 \mathrm{~mL}$ distilled water in glass containers and remained there at $37^{\circ} \mathrm{C} \pm 1^{\circ} \mathrm{C}$ for 24 hours, 7 days, or 30 days. Then, the discs were removed and washed with water. Thereafter, they were gently dried with absorbent paper and weighed again to obtain $\mathrm{m} 2$. Finally, the specimens were reconditioned to constant dry mass $(\mathrm{m} 3)$ in the desiccators using the cycle described above.

WSP and WSO were calculated by using the following equations provided by ISO 4049:2009 standard $^{13}$ :

$$
\mathrm{WSP}=\frac{m 2-m 3}{v}
$$

where $\mathrm{m} 2$ is the mass of the specimen after the period of immersion in water for 24 hours, 7 days, or 30 days; $\mathrm{m} 3$ is the final mass after drying the specimen; and $\mathrm{V}$ is the initial volume of the specimen.

$$
\mathrm{WSO}=\frac{m 1-m 3}{v}
$$

where $\mathrm{m} 1$ is the mass obtained after the initial drying and before the immersion in water of the specimen; $\mathrm{m} 3$ is the final mass of the specimen, and $\mathrm{V}$ is the initial volume of the specimen.

For the surface microhardness measurements, a Vickers microhardness tester with microscopic lens (Shimadzu HMV; Shimadzu Corporation, Tokyo, Japan) with a $200 \mathrm{~g}$ of load and 10-s dwell time. Five indentations were taken on the polished surface of each specimen and averaged to determine the hardness value of each specimen at the following time periods: before water immersion, after 24 hours, after 7 days, and after 30 days.

Vicker's hardness values were converted into microhardness values by the machine. All measurements were performed by the same operator in the laboratory conditions.
Two specimens from each polishing group from each tested CAD/CAM material were selected for scanning electron microscopy (SEM) analyses. The specimens were goldcoated with a high-vacuum metal sputter coater (EMS 550X, Electron Microscopy Sciences, Hatfield, PA, USA). Then, SEM analyses were performed with Zeiss Evo 50 analytic microscope (Carl Zeiss, Oberkochen, Germany). The images were taken with $\times 4000$ magnification.

Two datasets for the statistical analyses of WSP, WSO, and microhardness values were created for statistical analyses. Shapiro-Wilk test was applied to each dataset for the evaluation of the normal distribution of variables. Then, Levene test was used for testing the homogeneity of variances. Data were analyzed using statistical software SPSS version 16 (Statistical Package for Social Science, SPSS, Chicago, IL, USA). Two-way Analysis of Variance (ANOVA) taking such following factors as CAD/CAM materials (3 levels - LU, CS, VE) and polishing methods (5 levels, Group I, Group II, Group III, Group IV, and Group V) was applied since the pooled data of WSP and WSO were distributed normally. Additionally, post hoc Tukey's tests were performed when the effect of the main factors or the interaction reached significance.

The statistical differences in microhardness data among tested materials and polishing procedures were compared by Kruskal-Wallis tests. Further, when the P value from KruskalWallis test statistics are statistically significant among the groups, Mann-Whitney U tests were conducted for multiple pairwise comparisons.

The results of statistical analyses with $P$-values less than .05 were interpreted as statistically significant. But, for all possible multiple comparison tests, Bonferroni Adjustment was applied to control Type I error.

\section{RESULTS}

According to the statistical analysis, CAD/CAM materials exhibited different WSP values $(P<.05$; Fig. 2$)$. The order of overall WSP values amongst the tested materials were as follows: $\mathrm{LU}\left(15.02 \mu \mathrm{g} / \mathrm{mm}^{3}\right)>\mathrm{CS}\left(11.62 \mu \mathrm{g} / \mathrm{mm}^{3}\right)>\mathrm{VE}$ $\left(9.96 \mu \mathrm{g} / \mathrm{mm}^{3}\right)$.

Additionally, surface finishing and polishing procedures tested in this study significantly affected the WSP of the materials $(P<.05)$. The specimens in Group III (polished with yellow colored rubber-based silicon abrasives) had the highest WSP values whereas the specimens in Group IV (polished with diamond polishing paste) had the lowest. Furthermore, immersion period had significant effect on WSP values. Statistical analysis exhibited that the highest WSP results were obtained in the 30 days storage, while 24 hours results were the lowest.

Statistically significant differences were also found when two-factor interactions between CAD/CAM materials and polishing procedures $(P<.05)$ and $\mathrm{CAD} / \mathrm{CAM}$ materials and immersion periods $(P<.05)$ were evaluated.

Box-plot diagram of WSO values of the tested materials were given in Fig 3. The tested materials demonstrated sig- 


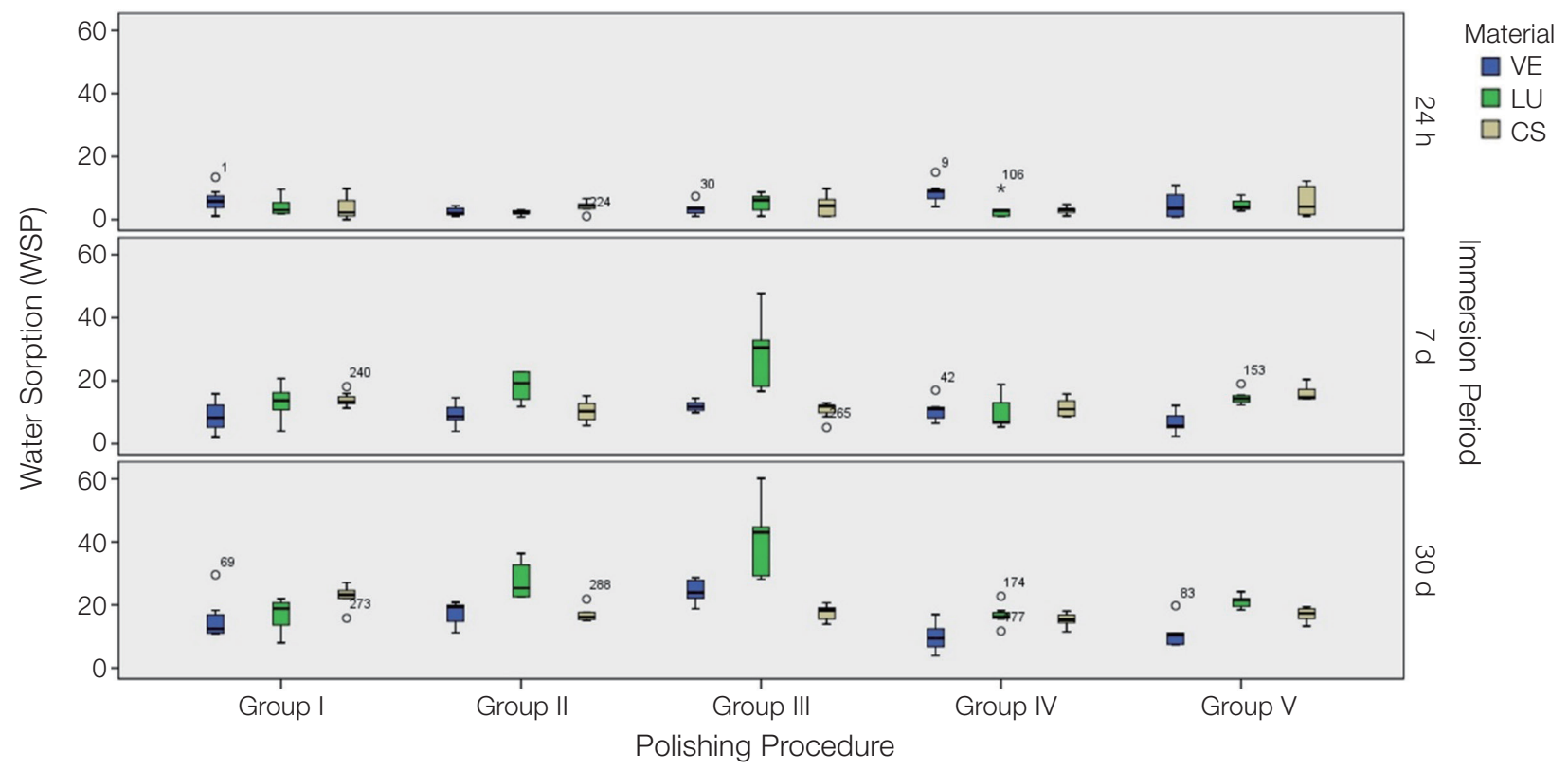

Fig. 2. Box-plot diagram of the distribution of WSP data according to tested groups. The central line in the box represents the median, and the box represents the middle $50 \%$ of values. The whiskers show the extent of the data. The black unfilled circles represent outliers.

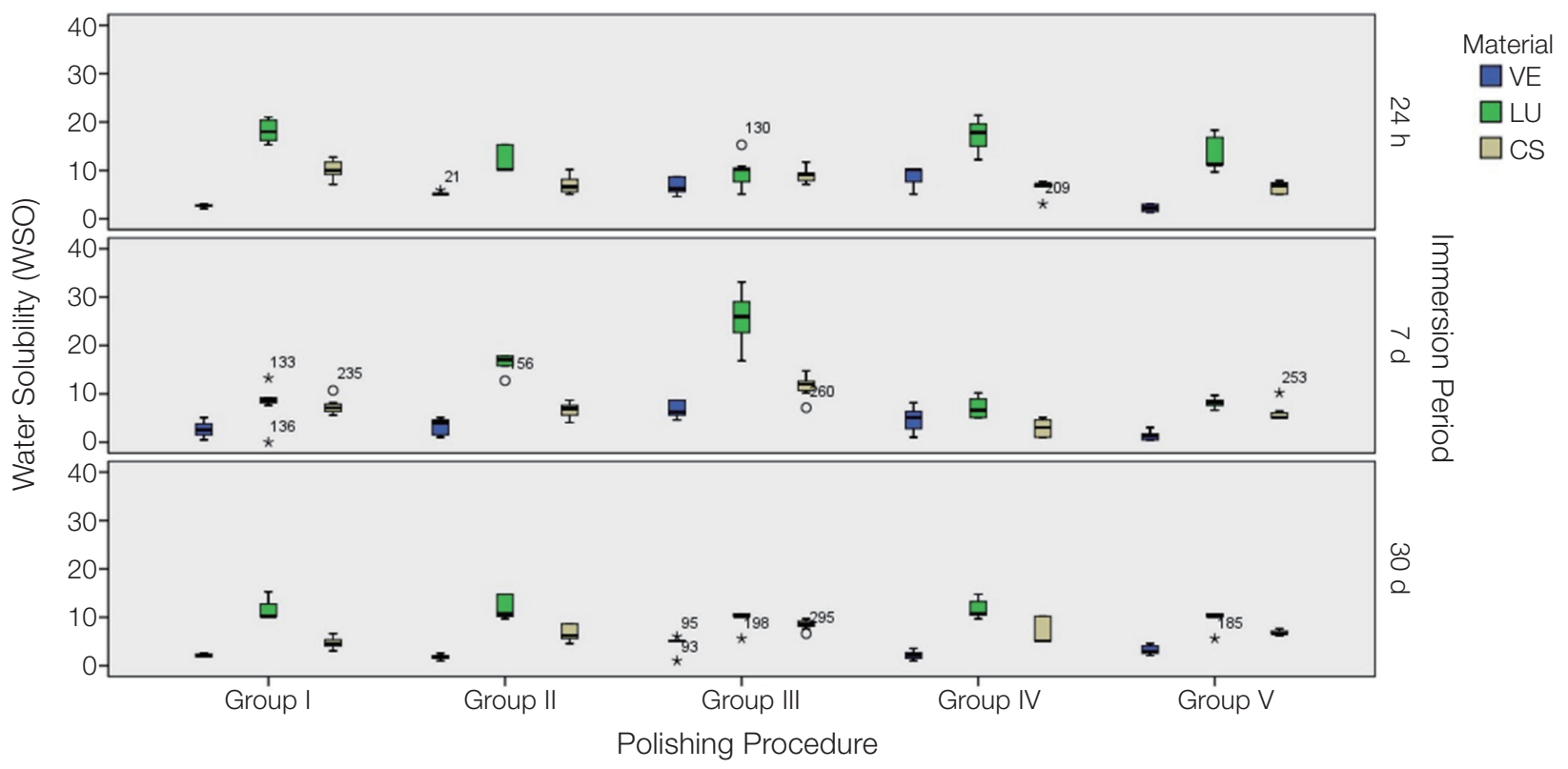

Fig. 3. Box-plot diagram of the distribution of WSO data according to tested groups. The central line in the box represents the median, and the box represents the middle $50 \%$ of values. The whiskers show the extent of the data. The black unfilled circles represent outliers.

nificantly different WSO according to the statistical analysis $(P<.05)$. When overall WSO values are evaluated, the materials were ranked as: LU $\left(12.7 \mu \mathrm{g} / \mathrm{mm}^{3}\right)>\mathrm{CS}(7.2 \mu \mathrm{g} /$ $\left.\mathrm{mm}^{3}\right)>\operatorname{VE}\left(3.87 \mu \mathrm{g} / \mathrm{mm}^{3}\right)$.

Besides, surface finishing and polishing procedures had statistically significant effect on the WSO results $(P<.05)$.
The order of WSO values respective to the polishing procedures were as follows: Group III (polishing with yellow colored rubber-based silicon abrasives) > Group II (polishing with diamond impregnated two-stage spiral polishing system) $\geq$ Group IV (polishing with diamond polishing paste) $\geq$ Group I (polishing with \#1200 and \#4000 grit SiC grind- 
ing papers) $\geq$ Group $V$ (polishing with aluminum oxide abrasive discs).

Furthermore, WSO data were significantly affected by immersion periods $(P<.05)$. Statistical analysis showed that the highest WSO values were observed after 24 hours period $\left(9.12 \mu \mathrm{g} / \mathrm{mm}^{3}\right)$, whereas the lowest values were seen after 30 days $\left(6.87 \mu \mathrm{g} / \mathrm{mm}^{3}\right)$.

Each material represented heterogeneous hardness level. According to the statistical analyses, independent from the finishing and polishing procedures, the ranking amongst the materials were as follows: $\mathrm{VE}>\mathrm{LU}>\mathrm{CS}\left(\mathrm{X}^{2}=154.928 ; P\right.$ $<$.001). Besides, significant differences were found amongst the finishing and polishing procedures $\left(\mathrm{X}^{2}=13.448 ; P<\right.$ .05). The specimens in Group IV (polished with diamond polishing paste) had the highest surface microhardness results whereas other groups had similar values $(P<.01)$. Additionally, non-significant differences were observed amongst the measurement periods $(P>.05)$. Inter-group comparisons revealed that the diamond impregnated twostage spiral polishing system yielded the highest surface microhardness values for CS and VE when the multiple effects of materials and finishing and polishing procedures were taken into consideration $(P<.001)$.

SEM results clearly demonstrated the influenced surface morphology created by the tested polishing procedures when compared to baseline. Fig. 4, Fig. 5, and Fig. 6 show the representative SEM images of the specimen's baseline surfaces of tested materials and of the tested polishing groups. CS had smooth surface textures with uniformly dispersed small particles (Fig. 4A). LU revealed larger cluster filler particles protruding from the surrounding surface (Fig. $5 \mathrm{~A})$. VE displayed brighter areas that belong to the ceramic network and darker parts that demonstrate the continuous polymer network (Fig. 6A). Polishing with diamond polishing paste resulted in the most regular and smoothest surfaces for all of tested materials (Fig. 4D, 5D, and 6D). Control (Fig. 4A, 5A, and 6A) and aluminum oxide abrasive (Fig. 4E, $5 \mathrm{E}$, and $6 \mathrm{E}$ ) groups followed this group. These groups showed small scratch lines and large areas of smooth surfaces. Conversely, the tested materials treated with diamond impregnated two-stage spiral polishing system (Fig. 4B, 5B, and $6 \mathrm{~B}$ ) and yellow colored rubber-based silicon abrasives (Fig. 4C, 5C, and 6C) presented deep grooves, diffuse irregularities, and the absence of smooth areas.
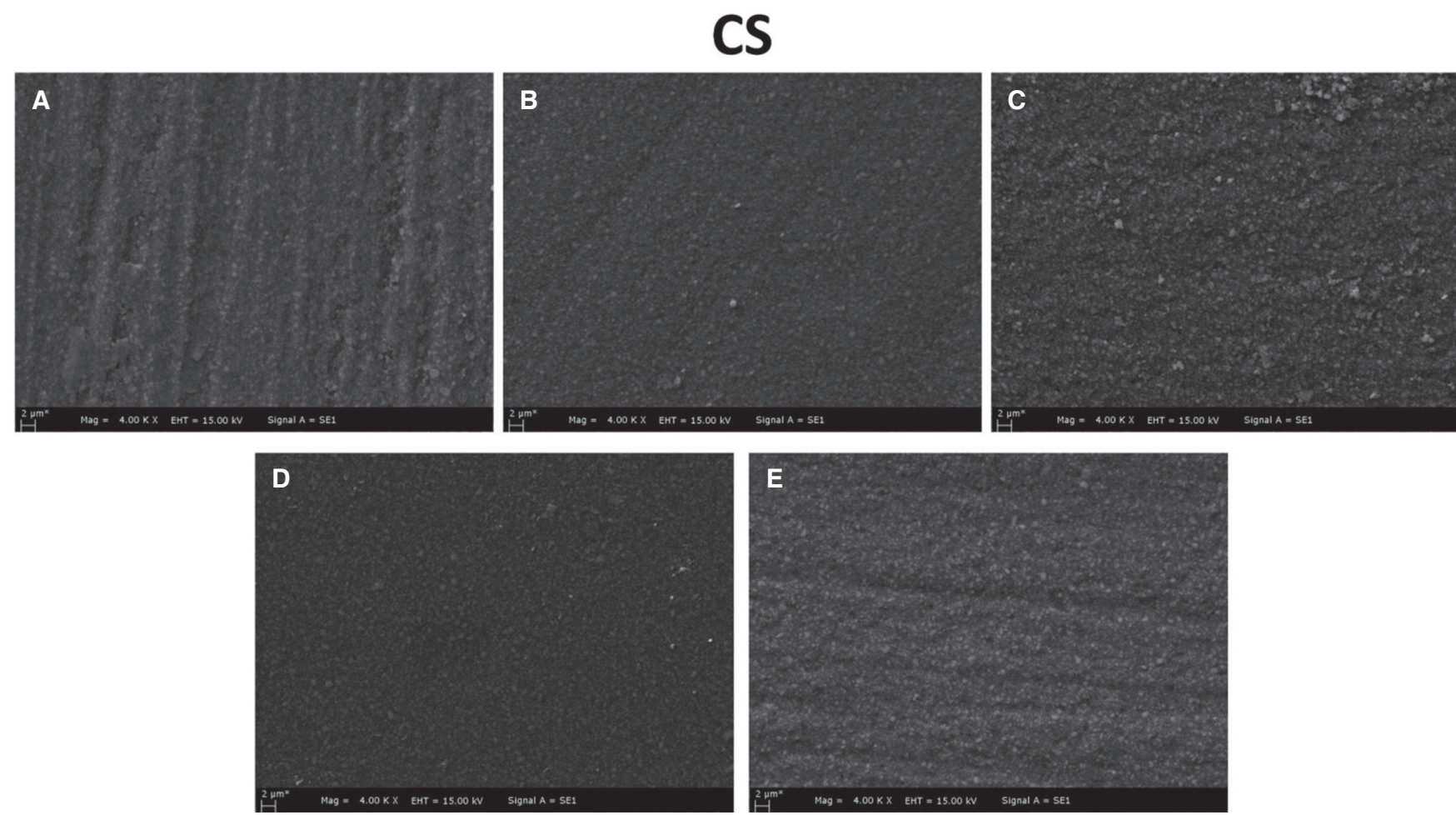

Fig. 4. Representative SEM micrographs in order to show the surface morphology of CS (GC Cerasmart) in each polishing group at $\times 4000$ magnifications. (A) Group I (Control), (B) Group II (diamond impregnated two-stage spiral polishing system) (C) Group III (yellow colored rubber-based silicon abrasive), (D) Group IV (diamond polishing paste), (E) Group V (aluminum oxide abrasive discs). 


\section{LU}
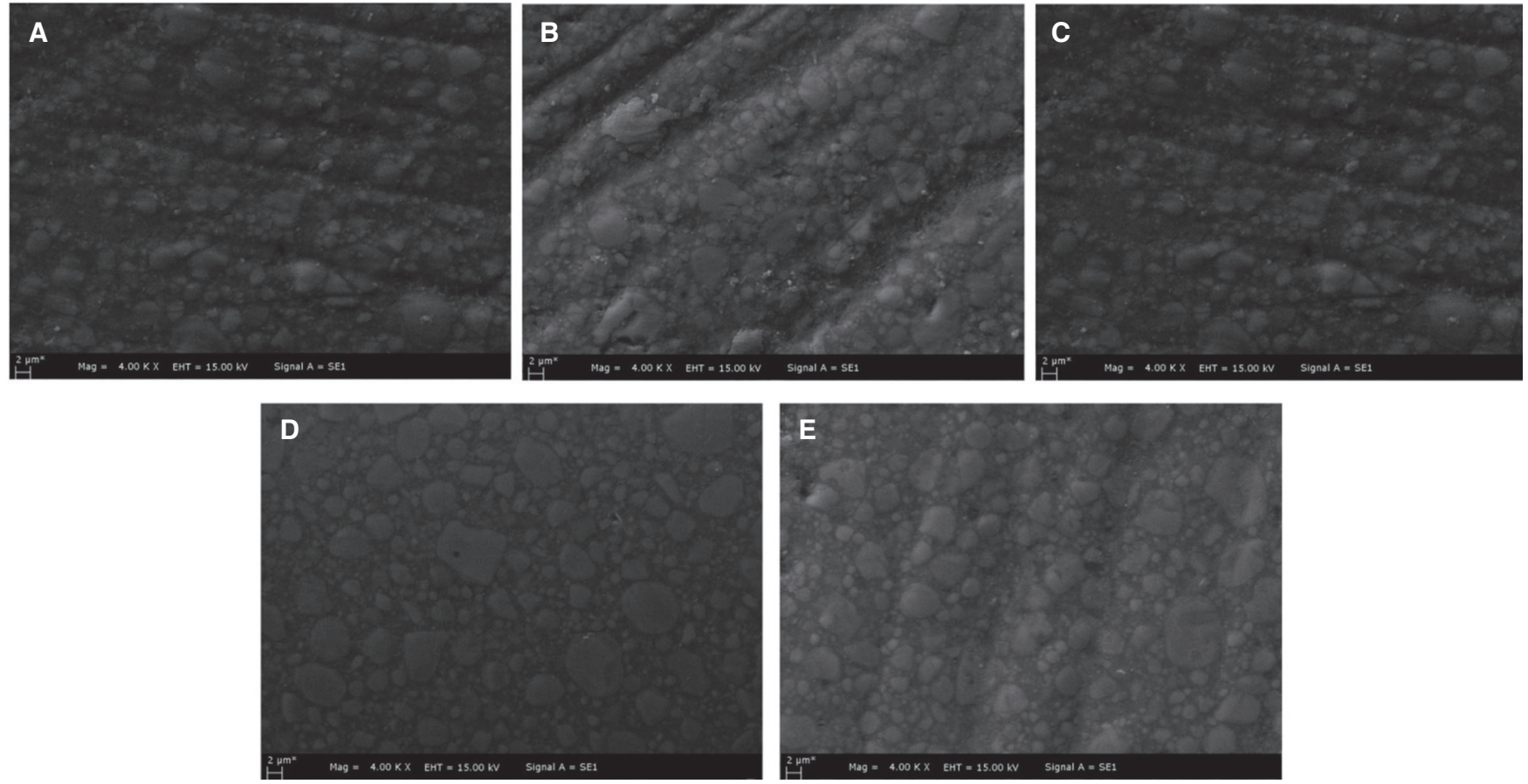

Fig. 5. Representative SEM micrographs in order to show the surface morphology of LU (Lava Ultimate) in each polishing group at $\times 4000$ magnifications. (A) Group I (Control), (B) Group II (diamond impregnated two-stage spiral polishing system), (C) Group III (yellow colored rubber-based silicon abrasive), (D) Group IV (diamond polishing paste), (E) Group V (aluminum oxide abrasive discs).
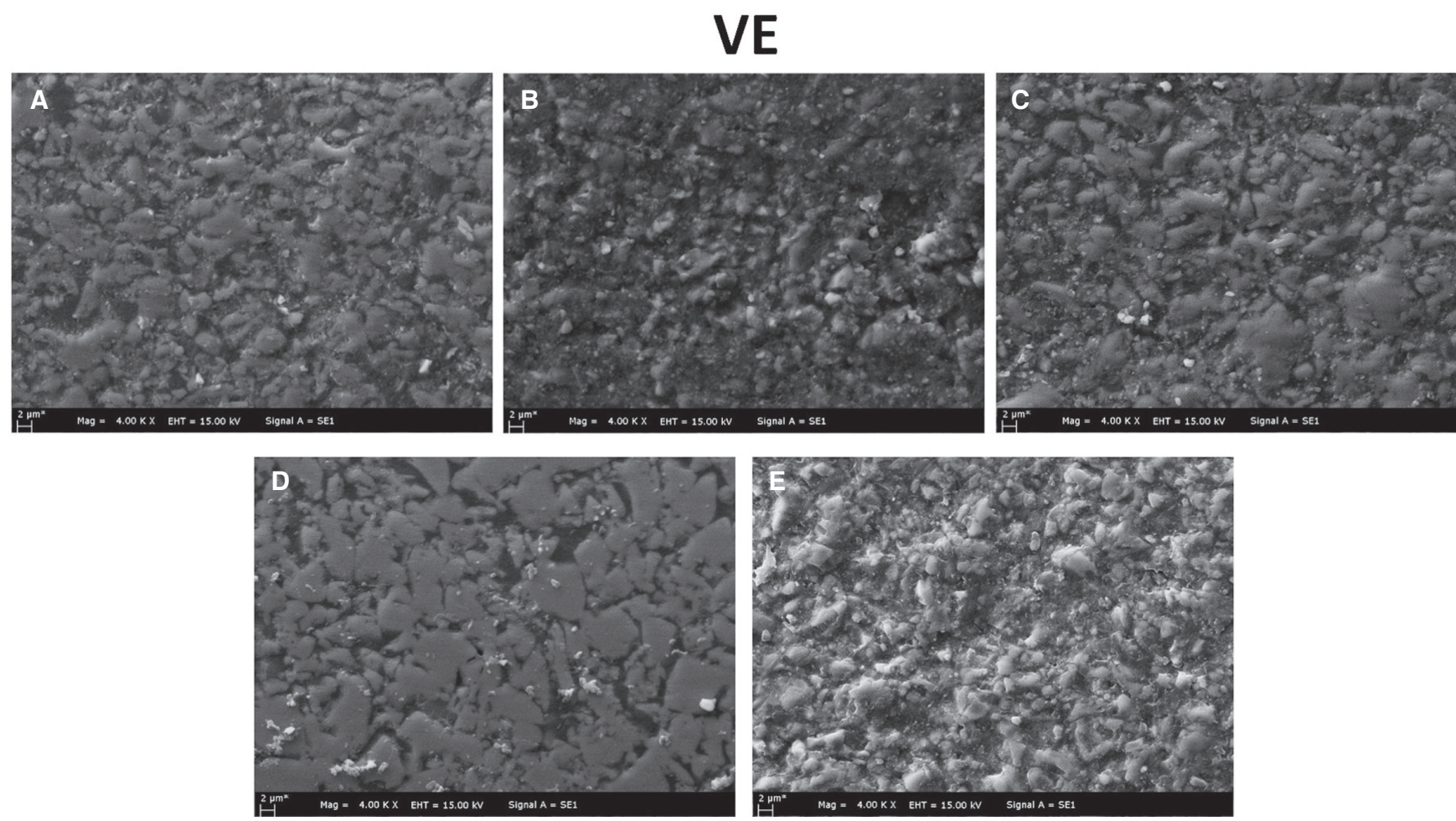

Fig. 6. Representative SEM micrographs in order to show the surface morphology of VE (Vita Enamic) in each polishing group at $\times 4000$ magnifications. (A) Group I (Control), (B) Group II (diamond impregnated two-stage spiral polishing system), (C) Group III (yellow colored rubber-based silicon abrasive), (D) Group IV (diamond polishing paste), (E) Group $\mathrm{V}$ (aluminum oxide abrasive discs). 


\section{DISCUSSION}

In the current study, the effect of different surface finishing and polishing techniques on WSP, WSO, and surface microhardness properties of three polymer based CAD/CAM materials were evaluated. Thermocycling was applied to all specimens in distilled water before the evaluations to imitate the natural oral environment during drinking and eating. Since the finding of this study exhibited WSP and WSO parameters were dependent on the tested CAD/CAM materials, the first hypothesis had to be rejected. Our results demonstrated WSP and WSO rates of LU significantly higher than those of CS and VE. Moreover, CS had significantly higher WSP and WSO than VE. These results could be attributed to water absorption properties of monomers. ${ }^{14}$ All of the tested materials consist of hydrophobic urethane dimethacrylate (UDMA) and hydrophilic triethylene glycol dimethacrylate (TEGDMA). ${ }^{15}$ TEGDMA exhibits higher water absorption and therefore permits water to penetrate into the resin matrix. ${ }^{16}$ However, WSP and WSO results of LU were the highest. LU contains Bis-GMA, distinct from VE and CS. Previous studies have shown that the water absorption potential of Bis-GMA was higher than those of UDMA, TEGDMA, and Bis-EMA. ${ }^{14}$ Therefore, the BisGMA monomer may be responsible for high values of WSP and WSO for LU.

In addition to the matrix composition, size of the fillers and filler content of the tested materials could be the reasons of their WSP and WSO behaviors. Alshali et al. ${ }^{5}$ have shown that filler loading and hydrophilicity of the resin matrix affected WSP and WSO properties of resin-composites. According to our results, the lowest WSP and WSO values were found for the polymer infiltrated network material, which has the highest filler content $(86 \%)$. Similar to our findings, Fleming et al. ${ }^{17}$ have reported that the increased filler content would result in the reduced water absorption and water solubility values of resin based composite materials. In this context, our results support the concept that water absorption generally increases with higher amounts of resin matrix and a lower amount of filler particles. $^{18}$

In this study, two nano-hybrid filled resin matrix ceramics (CS and LU) and a polymer infiltrated ceramic (VE) were selected. These materials have different crystalline structures: CS is a high-density composite material contains $29 \mathrm{wt} \%$ polymeric network with $71 \%$ silica and barium glass particles, LU combines aggregated zirconia and silica clusters and has no glass particles available for etching, whereas VE is composed of a dual network structure (ceramic and polymer) being $86 \%$ feldspathic porcelain by weight. As confirmed in this study, polymer infiltrated ceramic CAD/CAM material showed the lowest WSP and WSO rates, which may be related to its higher and more solid mechanical properties. $^{7}$ In addition, the microstructural arrangement of the fillers was shown to play an important role in the mechanical behavior of the resin based dental materials. ${ }^{19}$ Therefore, based on our results, one could assume that compositional differences between the CAD/CAM materials tested significantly influenced the WSP and WSO results.

Not surprisingly, increased WSO rates were observed in longer immersion periods, which are corroborated by the composite resin results from previous studies. ${ }^{5,18}$ Liebermann et al..$^{18}$ have indicated that the most obvious changes in the mechanical and physical properties of polymers could be expected within the first 30 days of immersion periods. Moreover the authors implied that 1, 7, 14, and 28 day immersion periods showed distinct hardness changes of the materials. ${ }^{18}$ Therefore, significantly different WSP and WSO results of immersion periods of the current study are in accordance with the previous findings. ${ }^{18}$

In a recent study by Egilmez et al., 73 weeks water storage, boiling in water, thermocycling $\left(5000\right.$ times, $\left.5-55^{\circ} \mathrm{C}\right)$ and autoclave treatment $\left(134^{\circ} \mathrm{C}, 200 \mathrm{kPa}, 12\right.$ hours, in distilled water) were shown to decrease the flexural strengths of CS and LU. Conversely, these aging methods had no effect on the flexural strengths of VE. Additionally, Takeshige et al..$^{20}$ demonstrated the retardation of crack propagation in composite structured dental materials under aqueous environments. The authors explained their findings by the presence of water in the resin matrix, which might inhibit crack propagation as resulting plasticization of the resin blunts the crack-tip and reduces the stress concentration and dissipates the crack. Despite this toughening mechanism, longterm deterioration of composites due to water absorption was also confirmed. Therefore, fatigue cracks in composites are less likely to be initiated under aqueous environments, but will rapidly propagate after initiation. From this point of view, polymer infiltrated ceramic CAD/CAM material, which exhibited the least WSO, could be assumed as the more resistant material than the other tested resin based CAD/CAM materials in this study. This assumption may also be supported by a previous study. ${ }^{7}$

The WSP and WSO of tested materials in this study are in the limits of ISO Specification $4049^{13}$ and ADA Specification No. $27^{21}$ (water absorption $<50 \mu \mathrm{g} / \mathrm{mm}^{3}$, solubility $<7.5$ $\left.\mu \mathrm{g} / \mathrm{mm}^{3}\right)$. However, WSP and WSO can cause molecular instabilities, which may lead to crack formations and a decrease in mechanical properties as already mentioned. ${ }^{7}$ Furthermore, water absorption not only affects physical and mechanical properties, especially of composite resins, but also decreases surface hardness and the elastic modulus. ${ }^{18}$

According to the current results, finishing and polishing instruments had a significant effect on WSP and WSO values of the tested materials. Therefore, the second hypothesis of this study was rejected. Effective polishing of resin based dental materials could be obtained when an abrasive removed the matrix resin as well as cut the relatively harder filler particles. ${ }^{22}$ Aluminum oxide discs were reported to be one of the most suitable polishing instruments for composite surfaces. ${ }^{23}$ However, the tested CAD/CAM material surfaces with Sof-Lex discs presented the dislodged particles, resin removal, and scratches (Fig. 5C, 6C, and 7C) in this study. In a recent study by Aytac et al., ${ }^{24}$ similar findings were obtained in microhybrid and nanohybrid composite 
resin surfaces with Sof-Lex discs.

On the other hand, yellow colored rubber-based silicon abrasives caused the highest WSP and WSO results. SEM images of this group presented irregular surfaces with deep scratches. Therefore, it can be concluded that the surface quality of the CAD/CAM material may be the reason of the different absorption and solubility results. In accordance with our study, in a previous study, rubber-based silicon abrasives have been shown to cause rougher surfaces than finishing and polishing discs. ${ }^{25}$

In the current study, polishing with diamond polishing paste resulted in the most regular and smoothest surfaces for all of the tested materials according to SEM images. Accordingly, the lowest WSP results were obtained in diamond polishing paste applied groups. Previous studies have reported that polishing systems with diamond abrasive particles or diamond polishing pastes created the smoothest restoration surfaces. ${ }^{26}$ Considering the significant interaction between the CAD/CAM materials and polishing procedures, final polishing by using diamond polishing paste can be recommended for all CAD/CAM materials.

According to our results, surface microhardness did not differ amongst the measurement periods. Conversely, CS and LU specimens are found to be softer than VE specimens. Moreover, the significant interaction between the CAD/CAM materials and polishing procedures led us to reject the third hypothesis. In the current results, diamond impregnated two-stage spiral polishing system yielded higher surface microhardness values than other tested polishing procedures for CS and VE materials. Lower values of the other tested polishing procedures might be explained by the thermal insults produced with rotary instruments during finishing procedures. ${ }^{23}$ In addition, temperature fluctuations by applied thermocycling could increase generated thermal stresses and lead to microcracks in the polymer structure or failures at the polymer/filler interface. ${ }^{27}$ Moreover, water exposure might result in autocatalytic surface degradation of the material or water absorption of the polymer matrix, ${ }^{27}$ which might explain the progression of surface softening. ${ }^{7}$

A limited investigation has been done with this study for the evaluation of different finishing and polishing procedures on WSP, WSO, and surface microhardness of polymer based CAD/CAM materials. One of the limitations of this study is the flat surfaces of the specimens. In clinical conditions, restorations have an irregular shape with convex and concave surfaces, and the efficiency of surface polishing procedures may be different under clinical circumstances. In addition, this study was performed in vitro, so the effect of oral environment was neglected. Thus, the results may not be directly comparable to the clinical situation. In addition to the methodological limitations, different biological conditions such as occlusal loads, changes in $\mathrm{pH}$ levels in the oral environment, the presence of saliva or bacterial adhesion to the restoration surfaces should also be investigated. Therefore, future studies are required.

\section{CONCLUSION}

Within the limitations of this study, water absorption and water solubility properties of the tested CAD/CAM materials were different. LU demonstrated the highest water absorption and water solubility results in the tested polymer-based CAD/CAM materials. In addition, surface finishing and polishing procedures tested in this study significantly affected the water absorption of the materials. The specimens polished with yellow colored rubber-based silicon abrasives had the highest water absorption results whereas the specimens polished with diamond polishing paste had the lowest ones. Furthermore, each material represented heterogeneous hardness level. Diamond impregnated twostage spiral polishing system yielded the highest surface microhardness values for CS and VE.

\section{ACKNOWLEDGEMENT}

The authors would like to thank Dr. Emine Kaygisiz for her valuable contributions to the SEM analysis.

\section{ORCID}

Mugem Asli Ekici https://orcid.org/0000-0002-0694-2141

Ferhan Egilmez https://orcid.org/0000-0001-9325-8761

Isil Cekic-Nagas https://orcid.org/0000-0002-2768-7207

Gulfem Ergun https://orcid.org/0000-0001-9981-5522

\section{REFERENCES}

1. Stawarczyk B, Awad D, Ilie N. Blue-Light transmittance of esthetic monolithic CAD/CAM materials with respect to their composition, thickness, and curing conditions. Oper Dent 2016;41:531-40.

2. Fasbinder DJ, Neiva GF. Surface evaluation of polishing techniques for new resilient CAD/CAM restorative materials. J Esthet Restor Dent 2016;28:56-66.

3. Vichi A, Fonzar RF, Goracci C, Carrabba M, Ferrari M. Effect of finishing and polishing on roughness and gloss of lithium disilicate and lithium silicate zirconia reinforced glass ceramic for CAD/CAM systems. Oper Dent 2018;43:90-100.

4. Acar B, Egilmez F. Effects of various polishing techniques and thermal cycling on the surface roughness and color change of polymer-based CAD/CAM materials. Am J Dent 2018;31:91-6.

5. Alshali RZ, Salim NA, Satterthwaite JD, Silikas N. Long-term sorption and solubility of bulk-fill and conventional resincomposites in water and artificial saliva. J Dent 2015;43:15118.

6. Tekçe N, Pala K, Demirci M, Tuncer S. Changes in surface characteristics of two different resin composites after 1 year water storage: An SEM and AFM study. Scanning 2016;38:694700 .

7. Egilmez F, Ergun G, Cekic-Nagas I, Vallittu PK, Lassila LVJ. Does artificial aging affect mechanical properties of CAD/ CAM composite materials. J Prosthodont Res 2018;62:65-74. 
8. Hampe R, Lümkemann N, Sener B, Stawarczyk B. The effect of artificial aging on Martens hardness and indentation modulus of different dental CAD/CAM restorative materials. J Mech Behav Biomed Mater 2018;86:191-8.

9. El Gezawi M, Kaisarly D, Al-Saleh H, ArRejaie A, Al-Harbi F, Kunzelmann KH. Degradation potential of bulk versus incrementally applied and indirect composites: color, microhardness, and surface deterioration. Oper Dent 2016;41:e195-208.

10. Toledano M, Osorio R, Osorio E, Fuentes V, Prati C, GarciaGodoy F. Sorption and solubility of resin-based restorative dental materials. J Dent 2003;31:43-50.

11. Poplawski T, Loba K, Pawlowska E, Szczepanska J, Blasiak J. Genotoxicity of urethane dimethacrylate, a tooth restoration component. Toxicol in vitro 2010;24:854-62.

12. Ruse ND, Sadoun MJ. Resin-composite blocks for dental CAD/CAM applications. J Dent Res 2014;93:1232-4.

13. ISO 4049. Dentistry - Polymer-based restorative materials. International Standards Organization (ISO); Geneva; Switzerland, 2009. Available at: https://www.iso.org/standard/42898.html

14. Gajewski VE, Pfeifer CS, Fróes-Salgado NR, Boaro LC, Braga RR. Monomers used in resin composites: degree of conversion, mechanical properties and water sorption/solubility. Braz Dent J 2012;23:508-14.

15. Belli R, Geinzer E, Muschweck A, Petschelt A, Lohbauer U. Mechanical fatigue degradation of ceramics versus resin composites for dental restorations. Dent Mater 2014;30:424-32.

16. Vasudeva G. Monomer systems for dental composites and their future: a review. J Calif Dent Assoc 2009;37:389-98.

17. Fleming GJ, Awan M, Cooper PR, Sloan AJ. The potential of a resin-composite to be cured to a $4 \mathrm{~mm}$ depth. Dent Mater 2008;24:522-9.

18. Liebermann A, Wimmer T, Schmidlin PR, Scherer H, Löffler P, Roos M, Stawarczyk B. Physicomechanical characterization of polyetheretherketone and current esthetic dental CAD/ CAM polymers after aging in different storage media. J Prosthet Dent 2016;115:321-8.

19. Rodrigues SA Jr, Ferracane JL, Della Bona A. Flexural strength and Weibull analysis of a microhybrid and a nanofill composite evaluated by 3- and 4-point bending tests. Dent Mater 2008;24:426-31.

20. Takeshige F, Kawakami Y, Hayashi M, Ebisu S. Fatigue behavior of resin composites in aqueous environments. Dent Mater 2007;23:893-9.

21. American Dental Association. Reports of councils and bureaus revised American National Standards Institute/American Dental Association specification no 27 for resin-based filling materials. 1988. p. 8-9.

22. Watanabe T, Miyazaki M, Takamizawa T, Kurokawa H, Rikuta A, Ando S. Influence of polishing duration on surface roughness of resin composites. J Oral Sci 2005;47:21-5.

23. Venturini D, Cenci MS, Demarco FF, Camacho GB, Powers JM. Effect of polishing techniques and time on surface roughness, hardness and microleakage of resin composite restorations. Oper Dent 2006;31:11-7.

24. Aytac F, Karaarslan ES, Agaccioglu M, Tastan E, Buldur M, Kuyucu E. Effects of novel finishing and polishing systems on surface roughness and morphology of nanocomposites. J Esthet Restor Dent 2016;28:247-61.

25. Egilmez F, Ergun G, Cekic-Nagas I, Vallittu PK, Lassila LV. Short and long term effects of additional post curing and polishing systems on the color change of dental nano-composites. Dent Mater J 2013;32:107-14.

26. Bottino MC, Valandro LF, Kantorski KZ, Bressiani JC, Bottino MA. Polishing methods of an alumina-reinforced feldspar ceramic. Braz Dent J 2006;17:285-9.

27. Rinastiti M, Özcan M, Siswomihardjo W, Busscher HJ. Effects of surface conditioning on repair bond strengths of nonaged and aged microhybrid, nanohybrid, and nanofilled composite resins. Clin Oral Investig 2011;15;625-33. 